\title{
Inclusive Co-Design within a Three-Dimensional Game Environment
}

\author{
Greg Walsh \\ Digital Whimsy Lab \\ University of Baltimore \\ Baltimore, MD USA \\ gwalsh@ubalt.edu
}

\author{
Craig Donahue \\ Digital Whimsy Lab \\ University of Baltimore \\ Baltimore, MD USA \\ craig.donahue@ubalt.edu
}

\author{
Zachary Pease \\ Digital Whimsy Lab \\ University of Baltimore \\ Baltimore, MD USA \\ zach.pease@ubalt.edu
}

\begin{abstract}
Co-design research with children is a field that continues to find new ground and expand as it explores new, and more effective ways to design. As children become more enveloped in a world of technology and video games, it follows to leverage these kinds of experiences for use in our design toolbox. In addition, continuing to explore how to include a larger global audience through distributed co-design can advance the design process. The study presented in this paper serves as a preliminary exploration of virtual sandbox game environments as a co-design tool. Utilizing a design inclusive research approach, we discuss what led us to explore this environment as a co-design tool, how it evolved over time, and our success in using it to include those who could not attend in-person sessions.
\end{abstract}

\section{Author Keywords}

Design; Children; Participatory Design; Minecraft

\section{ACM Classification Keywords}

D.2.2 Design Tools and Techniques: Evolutionary Prototyping

\section{INTRODUCTION}

Co-design with children is an important topic within the SIGCHI community. Researchers [11, 23, 26] have established various philosophies for designing with children in multiple ways. These philosophies are usually low-tech and enable children to express their ideas with tools that are accessible to them such as paper, crayons, and other art supplies. What about the other tools, the high-tech tools, that are often accessible to children in homes, schools, or libraries? How can researchers leverage this technology to include and engage children in the co-design process.

This work was completed as part of an intergenerational design team called KidsteamUB which is located in the city of

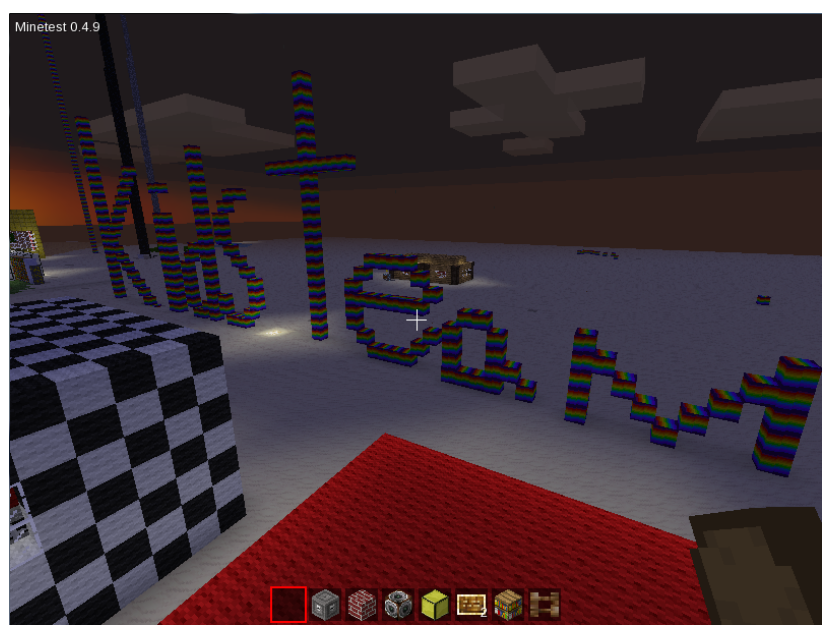

Figure 1. The Kidcraft environment

Baltimore, Maryland, USA. This project was directly influenced by the original Kidsteam [13] with an emphasis on designing with urban children. In this design group, children between the ages of 6 and 12 work with adult researchers in the design of new technologies and experiences for children twice a week for an entire school-year. The children who participate in KidsteamUB self-select. All of the children live within the geographical boundaries of the city of Baltimore, Maryland, which has a population of around 622,000 people and a median household income of just over $\$ 40,000$ USD [1].

First meeting in 2013-2014, this design group observed that the application of design techniques that require low-tech prototyping were not very popular with these children. Some of the children that joined KidsteamUB did not like to use art supplies to build low-fidelity prototypes. Instead, the child designers were very keen on utilizing high-tech tools, primarily the computer, to be creative. A number of the boys in the group talked endlessly about the game Minecraft [4], a popular game in which players build virtual worlds using blocks. Minecraft has become so popular that Microsoft announced the purchase of Minecraft's creator Mojang for \$2.5B USD [22] in September, 2014. Since this sale, Minecraft has expanded from personal computers to video game systems and mobile devices, surpassed 100 million registered users [3], and been promoted as an educational tool. 
As design researchers, we know that we need to continuously re-evaluate our methods to include more people in the participatory design process. If this group was so focused on technology, especially Minecraft, it only made sense to incorporate these technologies into the design sessions. This paper reports on the design and use of a customized three dimensional (3D) game environment that enables children and adults to co-design regardless of their location. In this paper, we describe previous work related to children and technology-based co-design, the motivations for the project, and the observed experiences and success of the environment.

The goal of this paper is to briefly discuss the history of the intersection of co-design and online technologies, explain the approach of the research, summarize the events of these studies, and discuss the findings. This paper gives others interested in this concept a starting point for developing their own systems.

\section{BACKGROUND}

For some time now, children have been included in various aspects of the technology design process. They have been users, testers, informants and design partners [11]. These roles enable children to participate at varying stages throughout the design process or through the whole process. At the same time, these roles enable design researchers to elicit feedback from children or work with them as full-partners in the cooperative design (co-design) of new technologies. In Druin's Cooperative Inquiry, children and adults designers work together as equal partners to develop new technologies for children [11].

\section{CSCW}

In order to understand how we can use co-design in a game environment, we need to reference the vocabulary that the Computer-supported Cooperative Work (CSCW) community uses to describe online collaboration. CSCW is "an endeavor to understand the nature and requirements of cooperative work with the objective of designing computer-based technologies for cooperative work arrangements" [27]. Rodden and Blair [24] describe that CSCW technologies take place over two dimensions: form of cooperation and geographical nature. The forms of cooperation deal with the temporal aspects of collaborative work as being synchronous, asynchronous, or mixed. In this case, synchronous means work is done at the same time and asynchronous means that work is done at different times by team members. The geographical nature dimension describes where the participants are in relation to each other.

Adapting cooperative inquiry into a $\mathrm{CSCW}$ environment necessitates an exploration of how the nature of such environments modify the forms and functions of traditional, face to face, co-design. In particular, research on the effects of CSCW communications mediums on workspace awareness, trust development, and engagement are of utmost importance, as these conditions are among the most likely to suffer, as compared to face to face work[15, 8, 18]. Additionally, some discussion of how the context of interaction is affected by
CSCW is warranted, to help better understand how the geographic nature and forms of cooperation affects co-operative inquiry.

Work space awareness is "the collection of up-to-the minute knowledge a person uses to capture another's interaction with the workspace" [14]. This is often taken for granted in faceto-face environments, such as those traditionally utilized by co-located participatory design groups. However, within a $\mathrm{CSCW}$ environment, it can become a limiting factor. Research has identified the mechanisms of workspace awareness as the ability to answer simple questions as to the who, what, when, and where of the shared workspace. Without the ability to acquire this information, the ability to cooperate can be greatly diminished or impeded [15]. For a CSCW workspace, maximizing the capacity for users to answer these questions can greatly increase users' workspace awareness, and consequently their ability to communicate effectively.

Benford et al. [7] discuss these considerations in environments for children by describing collaboration in KidPad, a collaborative drawing tool, and Klump, a collaborative, three dimensional amorphous modeling tool. Both of these tools enabled collaboration but did not encourage collaboration although this disconnect could be addressed through better awareness and shared interfaces. They describe that collaborative online systems have challenges in workspace awareness and shared interfaces because they need to 1) synchronize what users see, 2) synchronize object manipulations, and 3) make information about other users available to participants. They also mention that getting children to collaborate in computer systems could be a challenge if there is no shared goal between them.

The Scratch project from MIT's Media lab is an online tool for the design and dissemination of interactive web media. The online tool incorporates certain features relevant to the discussion. In particular, the "remix" feature of the Scratch environment, through which users can reconfigure another user's preexisting design without destroying the original copy, performs many of the functions desirable for a distributed co-design tool [21] while not actually supporting codesign. Although it does not support synchronous co-design, Scratch's solution to the re-use problem is an elegant one, and bears consideration for design decisions in the development of an online co-design system.

Trust as a concept within organizational research, and consequently CSCW research, is generally defined as the "willingness to be vulnerable, based on positive expectations about the actions of others". Such willingness is absolutely essential for the efficacious usage of cooperative inquiry but is again, heavily modified in a CSCW environment. Previous research suggests that the medium of communication in a CSCW environment affects trust between collaborating individuals within a CSCW setting. In testing, CSCW communications methods (Video, Audio, Text) showed diminished feelings of trust in participants as compared with face-to-face interactions. In particular, communication solely through text, i.e. a chat client, is associated with a marked decrease in self reported feelings of trust in test groups [8]. In the 
environment of cooperative inquiry, a method predicated on trust between equal design partners, accounting for this tendency is a concern. Designing communication avenues that allow for communications that instill trust between participants, particularly contextual and deictic information, seems integral to the development of a CSCW cooperative inquiry environment.

Of particular concern in the course of this research are the ways in which the use of technological tools to facilitate interaction fundamentally changes the nature of the interactions. Research on the effects of digitally mediated interaction have observed a number of ways in which the experience diverges from traditional face-to-face interactions. Grudin discusses at length the ways in which digitally mediated interactions de-contextualize interactions, while LeeTiernan observed how users engagement is often diminished in a CSCW environments [18, 12]. An awareness of these tendencies in CSCW environments should inform subsequent design decisions in the development of a tool for distributed codesign. The development of tools that allow participants to "re-contextualize" communications, through whatever mechanism, seems necessary for a CSCW co-design environment to approximate the dynamics of face-to-face interactions.

Taken together, the CSCW research reveals a number of factors that modify interactions in the migration from face-toface to digital environments. Research reveals a variety of hurdles and impedances to the replication of face-to-face interactions, as well as a number of possible strategies to obviate them. While little research exists on the effects of CSCW on cooperative inquiry, it is hoped that this research can further ideas and designs by examining the intersection of the two.

\section{Distributed Participatory Design}

Distributed participatory design is an under-researched area of the overall landscape. While some pioneering work was done by Muller et al. in the early 90's with the PICTIVE interface [19], it wasn't until recently that researchers began exploring the possibilities and implications of distributed participatory design tools. While most of this research is still in the exploratory stage, some interesting endeavors are currently underway.

Heintz et al. developed the "Participatory Design online tool" (PDot), a software interface for the application of participatory design principles in a distributed design context [16]. PDot enables user collaboration in the development of web application interfaces. Their team identified six user requirements necessary for distributed participatory design, and reviewed currently available web tools within this context. Heintz defines the six user requirements as:

1. Interactivity: Work with interactive prototypes as opposed to static images.

2. Annotation: Enable a participant to give textual feedback as well as relate it to a specific interface element.
3. Creativity: Support drawing (to provide graphical feedback) and more advanced prototype editing (e.g. adding or moving components).

4. Collaboration: Allow users to provide annotations collaboratively.

5. Access: Be easily accessible from anywhere with Internet connection, and work without installation.

6. Instructions: Offer instructions to get the user started; to support users in their exploration task in the absence of a developer.

Some of these elements were explored by other researchers in previous work [28] to understand how traditional co-design techniques could be adapted for geographically distributed, asynchronous use. The authors of that study utilized asynchronous forms of collaboration in order to support design between time zones and limited their work to two dimensional tools. The study did not look at three dimensional tools nor how synchronous technologies could be harnessed in order to facilitate distributed co-design.

In another example of co-design, the United Nations Human Settlements Programme in collaboration with the developers of Minecraft created a partnership called Block by Block [2] to promote sustainable development and public participation in the design process. In this partnership, professional developers build Minecraft models of communities and those worlds are brought to workshops where children are able to interact with them and design common spaces such as markets or playgrounds. Those designs are brought to architects and city planners and used as input in the final designs. The program works more like a "fill-in-the-blank" worksheet where most of the work is already done by experts and leaves an area for design by child designers. This does help participants visualize the design space [10]. This program does not appear to support collaborative co-design and is limited to the input of those that attend the events. With our motivation to use a game for co-design, we posit that the synchronous nature of 3-d multi-player games as well as their persistent worlds could be leveraged as a base for our distributed design sessions.

\section{PROCESS}

In order to address our technology-focused group, we explored new technology-based tools to enable collaborative design. The adult team members evaluated online environments to use in KidsteamUB to complete four phases of research: one co-located session with the popular children's site Roblox, a co-located design session using an open source clone of Minecraft called Minetest, a week-long design session that took place within the Minetest game world, and a preliminary test of custom designed software for collaboration.

This project followed a Design Inclusive Research [17] approach in order to investigate using a game environment as a platform for intergenerational co-design. In this approach, prototypes become means of creating knowledge in both the general phenomena of design as well as direct solutions to 
problem. The prototypes were developed using sampling techniques and then synthesis (See [9] for more information on the concept.)

In each of the phases, adult researchers worked as participants with the child design partners to design new things. The design goals were intended to be interesting to the children but complex enough to test the environments for suitability in codesign activities. (See Table 1 for a list of design goals in each phase.) Our goals were to design a system that enabled co-design and, simultaneously, reach those goals through codesign.

In the first three phases, there were eight child participants ( two girls and six boys) who were between the ages of seven and eleven years old. There were five adult participants: one university faculty member, three graduate students, and one undergraduate student.

Besides working as design partners, the adults were also tasked with taking notes and making observations about how the design process progressed through the use of prototypes. In co-located sessions, one researcher walked around and took pictures and videos of the different teams for later analysis. At the end of all co-located sessions, the entire design team would get together and debrief about the experiences of the day. Those experiences were written on a whiteboard at the front of the group. During the online sessions within the game-based world, adult researchers also participated and observed but were aided with system logs and screenshots of the activities. The notes, photographs, logs, and recordings were analyzed for content and used to construct the narrative of the development and evaluation of the prototypes.

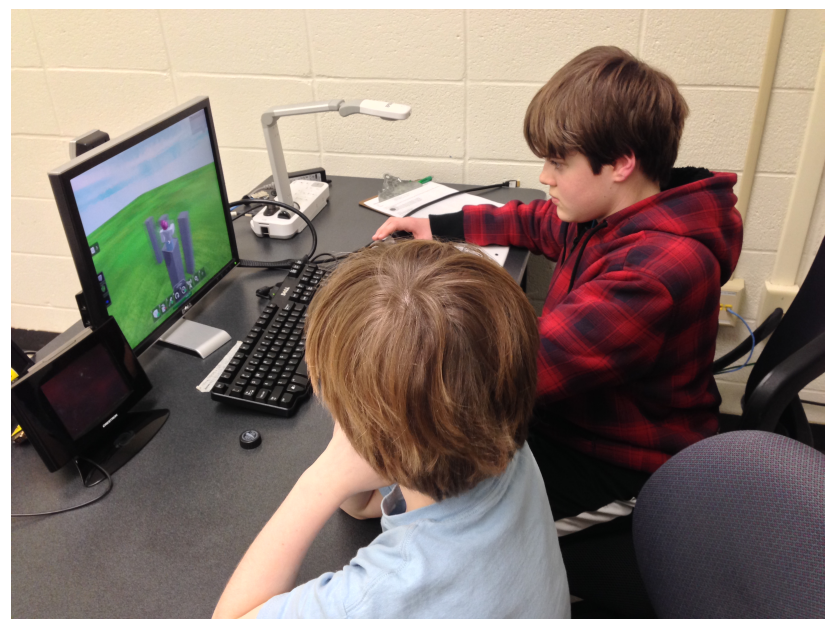

Figure 2. Design partners interacting with Roblox.

\section{Phase 1 - Roblox}

In Phase 1, the research team wanted to use an existing game world as a prototype in order to explore the user experience and feasibility of co-design within. Roblox [6] , a popular and free pre-existing block-building platform was chosen for use. We chose this tool because of its popularity with different age groups as well as its flexibility in building. For this activity, the child design partners were split into three groups, two groups of two and one group of three. They were then asked to use this tool to create their own zoo. Each group was then paired with an adult design partner who would design with them. Designers were free to create as they saw fit and there were no limitations on the number or types of exhibits they could create in their zoo.

At the end of the design session, each group had created a single exhibit. Because Roblox is meant as a single player experience, the design partners were required to take turns controlling the mouse while sharing the computers (See Figure 2). In order to simulate an asynchronous design session, each group moved to the computer of another group to expand upon that group's design. All child design partners showed a great amount of initial possession over their projects, but were willing to switch to different computers and expand on the other design. However, once work began on their new projects, it became very evident that there was a lack of trust of their fellow partners working on their original designs.

Although partners continued to work on their new designs, conversations across the room continued as partners asked other groups not to "mess up" what they had already created or harshly criticized other groups' improvements upon their original design. Once the design time was finished, everyone regrouped and a discussion was initiated about the software we used and how well it worked with our design process.

Based on the post-design discussion, the child design partners enjoyed using Roblox as a design tool. They felt as though they could use this tool to create "anything" and that it was very easy to just pick up and use. On top of this, they also were thrilled about the opportunity to virtually create with others (multiplayer) and express their creativity. One of their biggest concerns was to keep "other" people out of the system. In particular they were concerned with strangers getting access to this online content. This may be a reaction to their upbringing in an urban environment or the increased concern of parents for safety [25]. Even though they felt like Roblox gave them the tools to create "anything," they still wanted more out of the experience such as the ability to fly, animals and plants. Some of these desires stemmed directly from the zoo-themed topic of the design session. The other requested features appeared to come out of their knowledge of the game Minecraft. In order to continue our research into co-design, we decided to explore new potential software that we could use to leverage this type of play experience as a design tool. The most logical tool was to use Minecraft as it was familiar to our participants and "met" our designers in a realm that was familiar to them.

\section{Phase 2 - Minecraft Clone}

For the second phase of our research, we created a customized, multiplayer game world hosted on a private server using the free and open source Minecraft clone, Minetest [5] We called this world Kidcraft as a portmanteau of Kidsteam and Minecraft. Due to its similarity to the popular Minecraft game, all of our child design partners were at least somewhat familiar with the functionality of this environment and the open source nature of Minetest reduced our software licens- 


\begin{tabular}{llll}
\hline Phase & Tool & Location & Design Goal \\
\hline 1 & Roblox & Co-located & Zoo Exhibits \\
$2 \mathrm{a}$ & Minetest & Co-located & Re-creation of Design Lab \\
$2 \mathrm{~b}$ & Minetest & Co-located & Virtual Town \\
3 & Minetest & Geographically Distributed & Library for Future Design Team Members \\
4 & Web browser & Geographically Distributed & Robot for Science Experiments \\
\hline
\end{tabular}

Table 1. Comparison of different phases, their tools, and design goals.

ing costs for the project. This phase occurred over two colocated design sessions in our lab.

The first session of this phase gave our child design partners the chance to explore and familiarize themselves with Kidcraft through a simple design task. Design partners were split into three pairs and coupled with an adult design partner. For this session, our groups were given the design challenge to re-create the lab that we meet in during our design sessions. Adult design partners expressed their ideas as well as performed troubleshooting when child design partners got stuck or needed help to figure out controls. Most of this confusion came from knowledge of Minecraft functionalities and the slight differences to those available in Kidcraft.

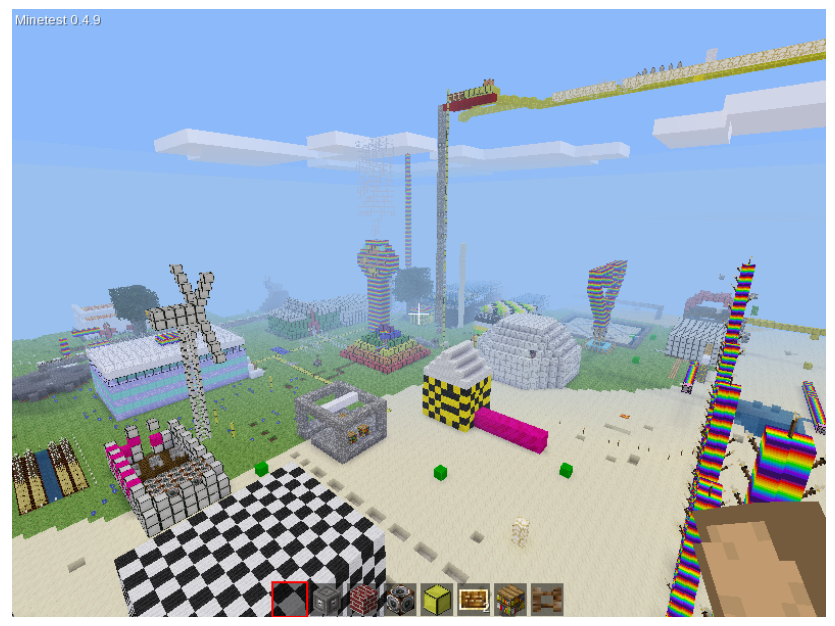

Figure 3. Aerial view of Kidcraft community village.

While each of the groups started with a generic outline of what they felt represented our design lab, such as four white walls, all the groups eventually took creative freedom and added a number of additions to their lab. Lab design additions included furnaces, a library with design books, a secret pool, whiteboards in the hallway, carpet, and a "thing." The reasoning behind these additions was simply a desire to have extra tools to help with the design process as well as generally just creating something fun. At the end of this design session we held a group discussion to see how the session went and to hear ideas on how it could be improved in future sessions. The initial response to the new software was mostly positive, but the slightly different controls made it difficult for the child design partners. Although all of the designers had said they were familiar with Minecraft, not all players were comfortable using the "WASD" keys for directional movement. Also, all partners wanted their avatar to fly. Other minor issues included a desire for a more organized inventory, including the ability to search through it, and the inclusion of more game items. Many of the items the partners wanted were based on items they knew existed in Minecraft including the ability to craft (or make complex building tools out of basic in-game elements), the core mechanic of that game.

After the first session, the adult team members further customized the Kidcraft world to include more items (additional blocks, AI characters \& animals) as well as flight. A flat, generic ground was created for the world in order to not have it look like a typical Minecraft world. This also enabled a blank canvas for our partners to build upon. With the new improvements, the design team was given the task of creating a virtual town or community in our updated virtual space (See Figure 3). This session gave us the opportunity to have each of our child partners to work at separate computers instead of sharing. During a pre-design discussion, we talked about what makes up a community or town and that discussion was used as a starting point for the design of our virtual community.

Much like we saw during our initial session with Roblox, our child design partners were quick to create something in this space that they could claim as their own which was typically a house. It wasn't until they had completed this personal item that they might move on to work on another project and some partners didn't even make it past this initial point. One participant worked on nothing but community projects, creating both a lava park and an aquarium. Two sets of our child design partners also worked on projects together, including a planetarium and an underground tunnel system.

At the end of this session, we felt confident that the game environment could support co-design in a co-located manner. In order to evaluate its effectiveness as a distributed co-design tool, we needed to have our design team use it outside of the lab.

\section{Phase 3 - Distributed design with Kidcraft}

In order to investigate the use of a game environment as a geographically distributed design tool, we chose a week where KidsteamUB was not meeting in-person and made the environment available on a private online server. Participants needed to connect to the Kidcraft server with the Minetest client software. Throughout the week, five of the eight children and three of the five adults logged on to Kidcraft server in order to participate.

Although the world was persistent and supported asynchronicity, we did schedule two synchronous design sessions within Kidcraft that occurred at the same meeting times as our co-located sessions met. The design goal of the sessions, 


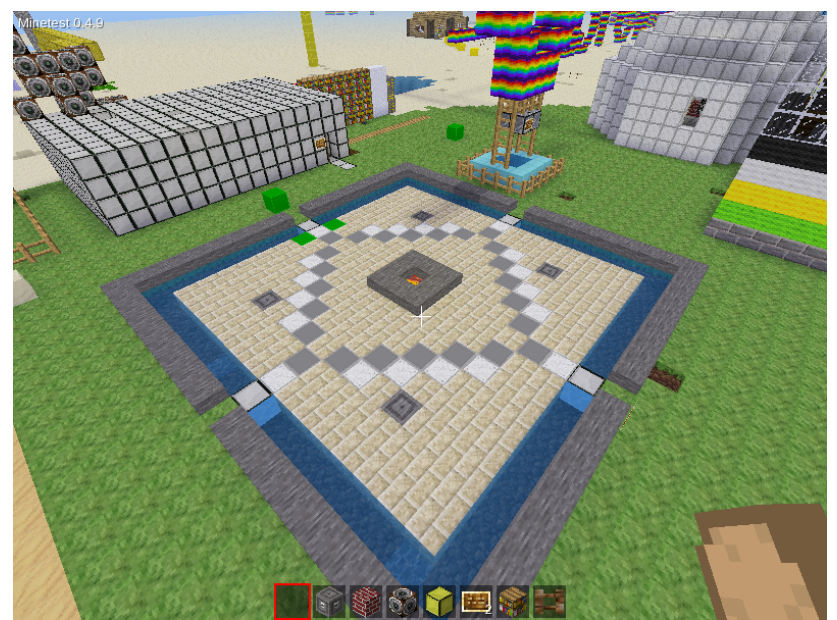

Figure 4. Kidcraft "Town Square” used for Circle Time

as well as the week in general, was to design a library that would be useful to new members of Kidsteam. Because we were not sure if the design team would actually collaborate or just build their own versions, we designated one area to be the design space and outlined it in bright colors as well as built a kiosk in the game that listed the design challenge.

Three child designers and two adult designers attended the synchronous session. The synchronous session ran similarly to a traditional, face-to-face design session. We held a predesign discussion in a town square to discuss the design challenge (See Figure 4). By developing a town square among the buildings that the children designed in the earlier session, we attempted to link the previous town-design sessions with this one and establish that Kidcraft is persistent and created for designing.

After the discussion, the design team flew to the designated area to begin designing and building the library (See Figure 4). The group started with a large space and, over the week, built a three-story library complete with a zombie librarian, books about crafts, and bathrooms (See Figures 6 and 5). Because members of the design team came in and out of the world, having a debrief became near impossible. In order to leave messages to other designers, team members made signs and placed them throughout the design. One participant, Amy, left a sign near Isaac's house that said "isaac's house of awesomenessWWWWWW". Besides compliments, these signs also helped the researchers to understand why some design decisions were made as well as generally what some items were meant to represent.

The team was able to communicate with one another through a text chat feature built into the tool. Although much of the text chat during the design times were about design challenges, the children would often chat about other topics such as scheduling sleep overs. Another interesting observation was a pair of design partners who are friends outside of Kidsteam initiated a phone call in order to better communicate: "do you want to talk on the fone[sic]" was answered by "sure if my mom was still here." The two continued to talk about their designs with the in-game chat.
During the synchronous design session, the chat logs reveal a greater sense of collaboration than was observed in the previous session. During the library activity, Isaac asked the group "what about we label the books into sections" in order to be inclusive in his design idea. Besides working in the world, the child design partners helped each other with technical questions about the environment such as how to move around or choose different tools. Not only did the group build on a library for new Kidsteam members, but, they broke off and worked on smaller projects. One 8 year-old child, Geoff, suggested "LET BILD SHIN THAT SES KIDSTEAM" or "Let's build a sign that says Kidsteam" to which another member agreed to build one with him. Although communication did occur, the spelling errors indicate how difficult spelling and typing can be for a child.

The design sessions became more and more asynchronous as the week went on. This was difficult because some team members did not attend the synchronous meetings at all. This could be due to a schedule conflict or just the wish to not participate in the design challenge and to instead use the design environment as more of a personal sandbox or game. In particular, we found an area that was a great distance (virtually) from the town that one participant had built his own house on. This participant would log in at night and build his own house designs instead of participating in the over arching design goal. We also learned that some of the team members had technical difficulty in running the client software, especially those using Mac OS Computers.

Another issue that appeared was the inadvertent destruction of the world by design partners. One of our design team members had not attended the in-person sessions because of his parent's change in work schedule and was not familiar with the Kidcraft world's controls, nor the different elements available to him. Unfortunately, he placed lava near someone's building burning it down as well as trying to use the water tool and flooding underground buildings. This led to one participant becoming very angry and writing "what $\mathrm{r} \mathrm{u}$ doing this is my house" and "im mad now".

This tool was used for several more design sessions over the following year. Nothing of note came from the design sessions themselves, however, its positive reception had us keep the world persistent for a number of months. The Kidcraft world was seen as a fun thing to play with when regular, inperson design sessions finished early or even while the participants were at home.

\section{Phase 4 - Moving away from a Game World}

To move towards a more complete co-design solution and away from a traditional game, the research team used the findings in the first three phases to build a Web-based, three dimensional environment inspired by Kidcraft. This environment shared several user interface paradigms with the Kidcraft world but removed many of the game based elements such as lava and monsters. The world continued to be block based but instead of the typical Minecraft building elements (such as dirt, grass, and rocks), the authors designed the environment with multicolored blocks that evoked a sense of technology similar to scenes in science-fiction movies. The world 


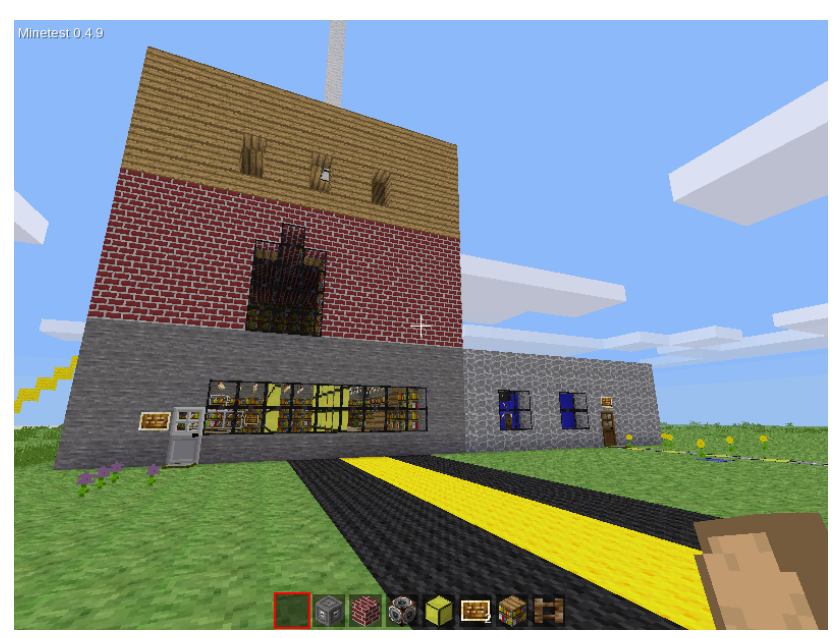

Figure 5. Outside view of the library created during Phase 3 design sessions.

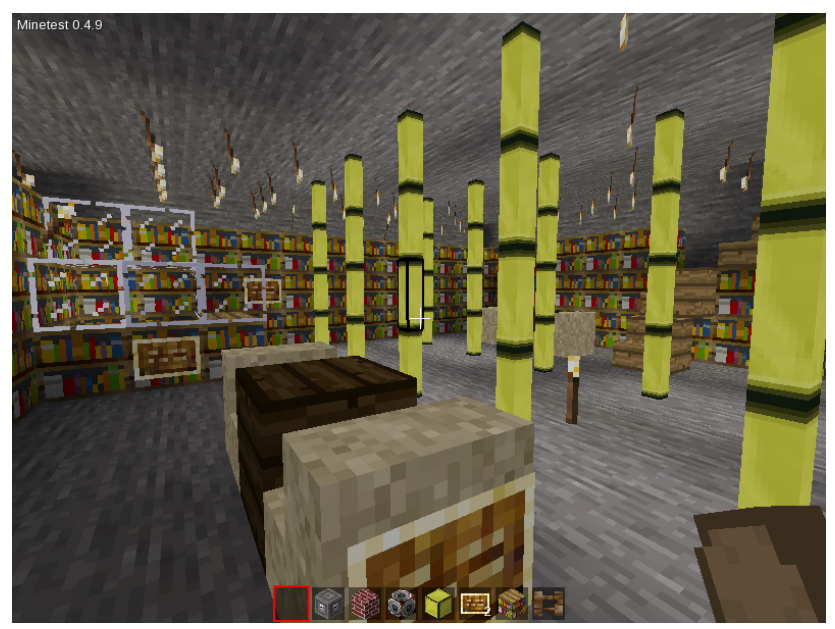

Figure 6. Inside view of the library. Assorted signs describing the environment can be seen throughout.

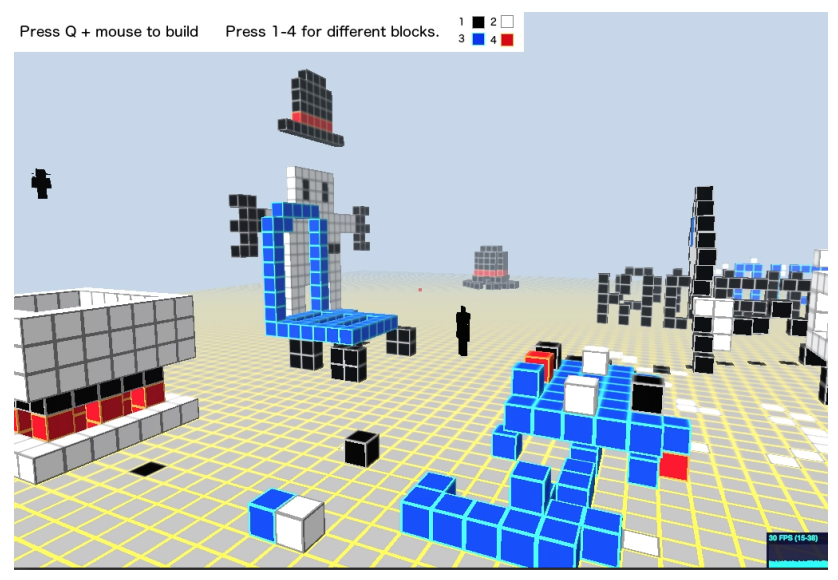

Figure 7. View of the designs from the browser-based tool.

also began with a finite size to reduce the chance of design partners going off on their own and instead design together. (See Figure 7 for an example of this tool.) This evokes the idea of Bendord et al.'s focus on encouraging collaboration instead of merely enabling it.

The environment was constructed using JavaScript through the NodeJS engine. It used several open source libraries and tools in order to create the three dimensional world. In order to address the need for better communication, we integrated audio chat along with text chat through a tool called Mumble. The world worked in a browser without any additional software, however, a separate mumble client was required for the audio and chat. The client was automatically activated when the world loaded in the browser and it was possible to connect only to the voice and text chat without being in the three-dimensional world.

Designers interacted with the environment in a manner similar to Minecraft. There was a first-person view that was displayed within the browser. When the designers moved their mouse around, the display would update as if they were looking around. In order to move forward, users pressed the "W" key on the keyboard. Users could also press the Space key on the keyboard to fly in order to enable three-dimensional movement and pressed the "Q" key on the keyboard while simultaneously clicking the mouse-button to place a block. Users clicked without pressing the key to remove a block. Participants could see other designers in the world as ninjas.

This phase consisted of all new children except one. There were three girls and four boys between the ages of six and twelve in this design team and all of them lived in Baltimore City. One boy could no longer attend due to his parent's work schedule and transportation issues in a similar fashion to a participant in the original phases of this research. In order to introduce the concept of Kidcraft, the group was given the final Minetest world to play with during a co-located session. The new, web-based prototype was introduced to the group through an online design session in which the design partners connected from their homes synchronously.

While no formal evaluation of the tool was done, we held a small geographically distributed, synchronous co-design session within the environment the Tuesday before the American holiday of Thanksgiving in order to try it out. Before the session, the adult researchers gave instructions to the children's parents on how to access the environment. Five child participants and three adult participants took part in the design session. Two adults and one child were co-located and all other participants took part from their homes. One child participant tried to access the environment from a tablet.

The design challenge for the session was to create a robot that children could use to investigate science. This design challenge was based on the real problem that researchers in the city have trouble investigating streams and water sources that were covered by storm drains and sewers. It also gave the participants something fun to design while providing the opportunity to evaluate the tool through the robot's design process.

There were several technical errors and two boys were only able to access the chat software with one, Charles, being able to type and one, Kevin, being able to chat and speak but both 
able to hear. The software supported text-to-speech so anything typed was spoken by a computerized voice for everyone to hear.

The group started by forming a circle for a pre-design meeting. As the pre-design meeting was taking place, the virtual world server crashed. We discussed the design challenge of the day as the server was rebooted. While waiting six minutes for the server to reboot, the entire group chatted about superfluous topics such as being sick and if anyone was eating a snack.

One adult started building a robot and discussed his design decisions. He offered options in order to signal the start of designing and involve the other designers. Once everyone was comfortable with the tool, those that were able to build began constructing the robot. The members of the group were keen to speak about their ideas and Kevin and Charles were able to give input through the voice and chat interfaces to contribute to the design. The design session lasted for 35 minutes and was cut short when the prototype crashed for the third time.

\section{FINDINGS}

In using a game environment for co-design, four important themes came to light: possession, availability, communication, and responsibility.

\section{Possession}

Possession was extremely important to the child designers. One thing that our in-person design sessions strive to emphasize is that the designs created by the group are part of a bigger whole and that the individual ideas become part of the group's idea. During the phases of Kidcraft, we found that the children were very keen on claiming something was theirs because they built it even though the environment enabled the group to work together. Children described different elements of their designs as "my": my house, my fountain, my sign. However, most of these references described the standalone things they built as individuals. Not until the accidental destruction in Phase 3 did feelings of possession really show, as usually friendly participants became angry at the loss of their designs.

This concern over possession echoes concerns over trust in a collaborative design setting. The wholesale destruction of one's design work would seem an obvious violation of the trust necessary for cooperative inquiry, and necessitates measures that prevent such disasters. The implementation of "locks" on design artifacts, with accompanying annotations, would seem prudent for a persistent virtual design environment. Additionally, a mechanism for reverting to a previous design state could be effective for trust development, and allow for temporally distributed design changes to be made without violating a co-designers trust through the unexpected modification or destruction of their efforts. This is similar to Scratch Online's remix feature [20].

\section{Availability}

Another important theme was availability. In-person Kidsteam takes place two days a week for 90 minutes but the persistent Kidcraft environment enabled the team members to participate whenever they were able to. Although we organized a synchronous design session with the tool, the team members came and went at different times over the week. The earliest logon by one of the children was just after 7:30AM and the latest was just before 7:45PM with most sessions starting after school. That means that the children were accessing Kidcraft within a window of 6 hours a day for 5 days.

This improved availability had three important consequences. First, the design team could take more time to develop their ideas and build the in-game prototypes necessary to convey their designs. This was most noticeable when the children would go back to the previous phase's projects and continue to work on their in-world house. The second consequence was that team members who had not been able to attend Kidsteam sessions in-person were now able to do so in the virtual environment. As mentioned, one team member's mother had an unexpected change of work schedule and he was unable to attend Kidsteam sessions in February and March. We invited him to the Kidcraft world and he was able to participate in our synchronous sessions and contribute to designs. The third consequence was that more availability of the tool led to more accidental destruction as there were not alway adult members of the team around to answer questions or recognize when someone was inadvertently damaging designs.

\section{Communication}

Communication was another important theme from our observations. In the game world, the designers communicated differently than in face-to-face Kidsteam. The use of chat in the world was helpful for communicating but the younger users had issues with typing. In order to combat this, our web-based prototype utilized voice and text-to-speech which participants seemed to like.

The possibility for the asynchronicity of designers in Phase 3 resulted in certain complications relating to a lack of workspace awareness and communication breakdowns. With designers using the virtual environment at different times, the level of awareness of other's work was reduced. Without a system of notifications for what work had been done recently by other designers, the users were left with an incomplete picture of the current state of development within the virtual environment. As a consequence, the work done often focused on individual's designs. Measures to increase users' overall workspace awareness and collaboration are necessary to improve the ease of collaboration. There was a notion of this in the designs of the library in Phase 3 as the design team used a number of annotation blocks to leave messages to each other and explain the design decisions.

\section{Responsibility}

The destruction of others' designs led us to the conclusion that co-design system designers need to achieve balance between capabilities and responsibility. In a virtual world with elements like lava, fire, pits, and other generally destructive forces, precautions need to be put in place to limit the damage that can be done from an erroneously placed item. Similarly, the designers need to be responsible in their own actions to 
not unintentionally destroy someone else's work. One way this was handled in our group was the creation of rules by the design team and posting them in the town square. A second way to ensure this was through the use of a tool that prevents others from editing or modifying elements placed by a designer within a certain radius. Because it is optional, it does not preclude several designers from working together on one project.

\section{A Game World as a Co-Design Space}

Due to the game-like experiences, there were constant requests for Minecraft features in the Kidcraft world. In particular, some of the child designers were interested in things like "survival mode" in which players start with nothing and survive in the virtual world by building and crafting new items in the game. As design researchers, we discussed with the team if these features would help them design to which they responded negatively. At some level, they were not interested in designing better but having game functions in the world. In a way, the use of something for design that was not necessarily created for design can be hindered by its own affordances. We decided to address this by designing an environment that is different enough from an existing game to not unintentionally prompt expected behaviors through similarities in user experience, but similar enough that very little learning would be required to operate from within the three dimensional world.

Using versions of Kidcraft, the team was able to meet and complete synchronous design projects as well as have the environment open for asynchronous development to accommodate different schedules of team members. More importantly, it follows that this flexibility extends to enable co-design by intergenerational design teams in different time zones. Taking that one-step further, groups in different geographical locations could hold synchronous design sessions and build from other groups' synchronous sessions at different times. A multi-user game environment that supports creating can be extended to enable opportunities for bringing participatory design to geographically distributed intergenerational groups.

\section{LIMITATIONS}

Our goal in this research was to investigate if children could use a three-dimensional game environment to participate in co-design sessions with the ultimate goal of including more voices in the design process. There are a few limitations to this exploratory research. First, this study took place on four different occasions: two individual structured design sessions, a one-week period of unlimited, unstructured designing, and a fourth synchronous remote design session. Second, the children that were part of our team had been design partners for less than six months. A longer study with more team members to evaluate this kind of co-design is needed to make generalizable claims.

Although this tool does not explicitly meet all six user requirements of distributed participatory design as outlined in [16], it did facilitate intergenerational co-design and was refined through co-design. Designers were able to be creative through manipulation of the interactive elements and were able to annotate them from within the environment. The designers were able to collaborate within the environment. As mentioned, the latter phases of the research were able to include participants who would have not been included in the design process otherwise. The ability to work without installing any software is a long-term goal of this project, yet the use of such software did not preclude the act of participatory design by itself. Instead, it may have prohibited MacOS users from logging in as there were only Windows and Linux clients available at the time of the research. This means that MacOS users would have had to either compile the client themselves or use complicated emulation technology to participate which is beyond most novice users' skills.

\section{CONCLUSION \& FUTURE WORK}

In this paper, we have outlined our work in using a game environment as a tool to support distributed co-design. The environment successfully supported one week of design sessions with children and extended the design sessions from synchronous meeting times to open, asynchronous activities. We found that this flexibility and accessibility from home enabled children who could not attend in-person sessions to continue to participate with the group. Future work on this topic will include further development of a web-based tool that does not rely on specialized client software. Additionally, the tool will need to borrow the affordances of a building game without setting the expectation of game-features that may be detrimental to design activities.

\section{SELECTION AND PARTICIPATION OF CHILDREN}

The children who participated in this research were members of KidsteamUB. Children volunteer to be part of KidsteamUB for one school year and can leave at any time. All of the children need to live within the bounds of Baltimore City and should be between 7 and 11 when they start. Parents provided consent for their children and the children assented to participate. The children participated in design sessions held in the Digital Whimsy Lab or from their homes in the online environment.

\section{ACKNOWLEDGEMENTS}

This research was made possible by the University of Baltimore Foundation and the Google Faculty Research Awards program. The authors would like to express their thanks to Emily Rhodes, Ashley Chisholm, and all the participants of KidsteamUB.

\section{REFERENCES}

1. Baltimore City QuickFacts from the US Census Bureau. Retrieved Jan 25, 2016 from http://www. census . gov/ quickfacts/table/PST045215/2404000, 00.

2. Block by block. Retrieved January 20, 2016 from http://blockbyblock. org/.

3. Minecraft passes 100 million registered users, 14.3 million sales on pc - gamespot. Retrieved on 01/21/2016 from http://www. gamespot. com/articles/ minecraft-passes-100-million-registered-users-14-3-milli 1100-6417972/. 
4. Minecraft. Retrieved January 25, 2016 from http://minecraft. net/.

5. Minetest. Retrieved January 15, 2016 from http: //www. minetest. net/.

6. ROBLOX. Retrieved September 16, 2014 from http: //www. roblox.com.

7. Benford, S., Bederson, B., Akesson, K.-P., Bayon, V., Druin, A., Hansson, P., Hourcade, J., Ingram, R., Neale, H., O’Malley, C., Simsarian, K. T., Stanton, D., Sundblad, Y., and Taxén, G. Designing storytelling technologies to encouraging collaboration between young children. In Proceedings of Conference on Human Factors in Computing Systems (SIGCHI), ACM Press (2000), 556-563.

8. Bos, N., Olson, J., Gergle, D., Olson, G., and Wright, Z. Effects of four computer-mediated communications channels on trust development. In Proceedings of the SIGCHI conference on human factors in computing systems, ACM (2002), 135-140.

9. Buxton, B. On long noses, sampling, synthesis, design, and innovation. Retrieved January 20, 2016 from http://2012 . uxlondon. com/programme/day1/billb/.

10. Crecente, B. How minecraft is helping the united nations improve the world - Polygon, April 2014. (Retrieved January 21, 2016 from http: //www.polygon.com/2014/4/22/5641044/ minecraft-block-by-block-united-nations-project.

11. Druin, A. The role of children in the design of new technology. Behaviour and Information Technology 21, 1 (2002), 1-25.

12. Grudin, J. Digitally mediated interaction: Technology and the urge system. In Affective minds: The 13th Toyota Conference, Elsevier (2000), 159-167.

13. Guha, M. L., Druin, A., and Fails, J. A. Cooperative inquiry revisited: Reflections of the past and guidelines for the future of intergenerational co-design. International Journal of Child-Computer Interaction (2012).

14. Gutwin, C., and Greenberg, S. Workspace awareness for groupware. In Conference Companion on Human Factors in Computing Systems, ACM (1996), 208-209.

15. Gutwin, C., and Greenberg, S. A descriptive framework of workspace awareness for real-time groupware. Computer Supported Cooperative Work (CSCW) 11, 3-4 (2002), 411-446.

16. Heintz, M., Law, E. L.-C., Govaerts, S., Holzer, A., and Gillet, D. Pdot: participatory design online tool. In CHI'14 Extended Abstracts on Human Factors in Computing Systems, ACM (2014), 2581-2586.
17. Horváth, I. Comparison of three methodological approaches of design research. In International Conference on Engineering Design, ICED 2007 (2007).

18. LeeTiernan, S., and Grudin, J. Fostering engagement in asynchronous learning through collaborative multimedia annotation. In Proceedings of INTERACT, Citeseer (2001), 472-479.

19. Miller, D. S., Smith, J. G., and Muller, M. J. TelePICTIVE: computer-supported collaborative GUI design for designers with diverse expertise. In UIST '92: Proceedings of the 5th annual ACM symposium on User interface software and technology, ACM (New York, NY, USA, 1992), 151-160.

20. Monroy-Hernández, A., and Hill, B. M. Cooperation and attribution in an online community of young creators. Computer (2010), 469-470.

21. Monroy-Hernández, A., and Resnick, M. Feature empowering kids to create and share programmable media. Interactions 15, 2 (2008), 50-53.

22. Ovide, S., and Rusli, E. M. Microsoft Gets 'Minecraft' - Not the Founders. Retrieved on September 19, 2014 from the Wall Street Journal: http://online.wsj.com/articles/microsoft-agrees-toacquire-creator-of-minecraft-1410786190.

23. Read, J. C. MESS days: Working with children to design and deliver worthwhile mobile experiences. UPA User Experience Magazine 9, 2 (2010).

24. Rodden, T., and Blair, G. CSCW and distributed systems: the problem of control. In Proceedings of the second conference on European Conference on Computer-Supported Cooperative Work, ECSCW'91, Kluwer Academic Publishers (Norwell, MA, USA, 1991), 49-64.

25. Rosin, H. The overprotected kid. The Atlantic (Mar. 2014).

26. Scaife, M., Rogers, Y., Aldrich, F., and Davies, M. Designing for or designing with? informant design for interactive learning environments. In Proceedings of the SIGCHI conference on Human factors in computing systems (1997), 343-350.

27. Schmidt, K., and Bannon, L. Taking CSCW seriously. Computer Supported Cooperative Work (CSCW) 1, 1 (1992), 7-40.

28. Walsh, G., Druin, A., Guha, M. L., Bonsignore, E., Foss, E., Yip, J. C., Golub, E., Clegg, T., Brown, Q., Brewer, R., Joshi, A., and Brown, R. DisCo: a co-design online tool for asynchronous distributed child and adult design partners. In Proceedings of the 11th International Conference on Interaction Design and Children, IDC '12, ACM (New York, NY, USA, 2012), 11-19. 